\title{
Successful reinstitution of agalsidase beta therapy in Fabry disease patients with previous lgE-antibody or skin-test reactivity to the recombinant enzyme
}

David Bodensteiner, $M D^{1}$, C. Ronald Scott, $M D^{2}$, Katherine B. Sims, $M D^{3}$, Gillian M. Shepherd, $M D^{4}$, Rebecca D. Cintron, $M D^{5}$, and Dominique P. Germain, $M D, P h D^{6}$

\begin{abstract}
Purpose: To determine if enzyme replacement therapy, involving intravenous infusions of recombinant human $\alpha$-galactosidase A (agalsidase beta; Fabrazyme ${ }^{\circledR}$ ), could be safely continued in patients with Fabry disease who had been withdrawn from a previous clinical trial as a precautionary, protocol-specified measure due to detection of serum IgE antibodies or skin-test reactivity to agalsidase beta. Methods: The rechallenge infusion protocol specified strict patient monitoring conditions and graded dosing and infusion-rate schemes that were adjusted according to each patient's tolerance to the infusion. Six males (age: $26-66$ years) were enrolled. Results: During rechallenge, five patients received between 4 and 27 infusions; one patient voluntarily withdrew after one infusion because of recurrence of infusion-associated reactions. No anaphylactic reactions occurred. All adverse events, including four serious adverse events, were mild or moderate in intensity. Most treatment-related adverse events occurred during infusions (most commonly urticaria, vomiting, nausea, chills, pruritus, hypertension) and were resolved by infusion rate reductions and/or medication. After participation in the study, all patients, including the one who withdrew after one infusion, transitioned to commercial drug. Conclusions: Agalsidase beta therapy can be successfully reinstated in patients with Fabry disease who have developed IgE antibodies or skin test reactivity to the recombinant enzyme. Genet Med 2008:10(5):353-358.
\end{abstract}

Key Words: Fabry disease, agalsidase beta, enzyme replacement therapy, lysosomal storage disease, X-linked disorder

Fabry disease (OMIM 301500) is an inherited lysosomal storage disorder that results from deficient activity of $\alpha$-galactosidase $\mathrm{A}(\alpha \mathrm{GAL})$ due to mutations of the GLA gene that encodes the enzyme. ${ }^{1}$ Enzyme replacement therapy (ERT), involving regular intravenous infusions of recombinant hu-

From the ${ }^{1}$ Division of Hematology/Oncology, University of Kansas Medical Center, Kansas City, Kansas; ${ }^{2}$ Departments of Pediatrics and Medicine, University of Washington School of Medicine, Seattle, Washington; ${ }^{3}$ Neurology Department, Massachusetts General Hospital and Harvard Medical School, Boston, Massachusetts; ${ }^{4}$ Department of Medicine, Weill Medical College of Cornell University, New York, New York; ${ }^{5}$ Pharmacovigilance Department, Genzyme Corporation, Cambridge, Massachusetts; and ${ }^{6}$ University of Versailles - St Quentin en Yvelines; Centre de référence de la maladie de Fabry et des maladies héréditaires du tissu conjonctif, Hôpital Raymond Poincaré (AP-HP), Garches, France.

David Bodensteiner, MD, Division of Hematology/Oncology, University of Kansas Medical Center, 2330 Shawnee Mission Parkway, Westwood, KS 66205.E-mail: dbodenst@kumc.edu.

Dominique P Germain, MD, PhD, Unité Fonctionnelle de Génétique Médicale, Hôpital Raymond Poincaré, 104 Boulevard Raymond Poincaré, 92380 Garches, France. E-mail: dominique.germain@rpc.aphp.fr.

Disclosure: David Bodensteiner declares no conflict of interest; C. Ronald Scott, Gillian M. Shepherd, and Dominique P. Germain are consultants for Genzyme Corporation; Katherine B. Sims is in Genzyme Speakers Bureau; and Rebecca D. Cintron is an employee of Genzyme Corporation.

Submitted for publication December 5, 2007

Accepted for publication February 22, 2008.

DOI: 10.1097/GIM.0b013e318170f868 man $\alpha$ GAL (agalsidase beta; Fabrazyme ${ }^{\oplus}$ ), has been developed as a treatment for Fabry disease. ${ }^{2-5}$ Because the gene encoding $\alpha \mathrm{GAL}$ is $\mathrm{X}$-linked, hemizygous males lack normal expression of the wild-type protein, whereas heterozygous females may express both wild-type and mutant forms of the enzyme. ${ }^{6}$ Immune responses to recombinant $\alpha \mathrm{GAL}$ can be anticipated in this patient population, and immunologic assessments were included as part of safety monitoring in clinical trials of agalsidase beta. As a precautionary measure, study protocols specified that patients were to be withdrawn from the study if they experienced adverse reactions during infusions and were found to have developed IgE antibodies or skin-test reactivity to agalsidase beta. This conservative approach was taken because the risk to patients for severe or life-threatening reactions was unknown. Because ERT is currently the only approved therapy aimed at the etiology of this serious, life-threatening genetic disease, a study was subsequently designed to evaluate the ability to reinstate agalsidase beta therapy in these patients using a rechallenge protocol that used strict monitoring conditions along with graded dosing and infusion-rate schemes that were adjusted in accordance with each patient's tolerance to the infusion. The results of the rechallenge study and follow-up on the study patients are reported here. 
Table 1

Overview of the rechallenge protocol

\begin{tabular}{|c|c|c|c|c|}
\hline Infusion number & Infusions 1 and 2 & Infusions 3 and 4 & Infusions $5-8$ & Infusions 9-27 \\
\hline Maximum dose of agalsidase beta & $0.5 \mathrm{mg} / \mathrm{kg}$ & $1.0 \mathrm{mg} / \mathrm{kg}$ & $1.0 \mathrm{mg} / \mathrm{kg}$ & $1.0 \mathrm{mg} / \mathrm{kg}$ \\
\hline \multirow[t]{2}{*}{ Interval between infusions } & 1 week between infusions 1 and 2 & 2 weeks & 2 weeks & 2 weeks \\
\hline & 2 weeks between infusions 2 and 3 & & & \\
\hline \multirow[t]{2}{*}{ Infusion rate } & $\leq 0.01 \mathrm{mg} / \mathrm{min}$ for the first $30 \mathrm{~min}$ & $\leq 0.25 \mathrm{mg} / \mathrm{min}$, as tolerated & Begin at $0.25 \mathrm{mg} / \mathrm{min}$ & Begin at $0.25 \mathrm{mg} / \mathrm{min}$ \\
\hline & $\begin{array}{l}\text { If tolerated, double the rate at } 30 \\
\text { min intervals to a maximum } \\
\text { rate of } 0.25 \mathrm{mg} / \mathrm{min}\end{array}$ & & $\begin{array}{l}\text { Increase by } 0.08 \mathrm{mg} / \\
\text { min at each infusion, } \\
\text { as tolerated }\end{array}$ & $\begin{array}{l}\text { Increase by } 0.08 \mathrm{mg} / \mathrm{min} \\
\text { at each infusion, as } \\
\text { tolerated }\end{array}$ \\
\hline Infusion duration & $\begin{array}{l}\text { Depends on body weight }(\sim 4-5 \mathrm{hr} \\
\quad \text { for } 70 \mathrm{~kg} \text { man })\end{array}$ & $\begin{array}{l}\text { Depends on body weight } \\
\quad(\sim 4-5 \mathrm{hr} \text { for } 70 \mathrm{~kg} \text { man })\end{array}$ & $2 \mathrm{hr}$ minimum & $2 \mathrm{hr}$ minimum \\
\hline Infusion set-up & IV pump with Y-tube connector & $\begin{array}{l}\text { IV pump with Y-tube } \\
\text { connector }\end{array}$ & $\begin{array}{l}\text { IV pump with Y-tube } \\
\text { connector }\end{array}$ & $\begin{array}{l}\text { IV pump with Y-tube } \\
\text { connector }\end{array}$ \\
\hline $\begin{array}{l}\text { Preinfusion prophylaxis for infusion- } \\
\text { associated reactions (IARs) }\end{array}$ & Prohibited & Prohibited & Allowed & Allowed \\
\hline Postinfusion observation period & $2 \mathrm{hr}$ minimum & $2 \mathrm{hr}$ minimum & $2 \mathrm{hr}$ minimum & $1 \mathrm{hr}$, in absence of IARs \\
\hline \multirow[t]{2}{*}{ Patient monitoring } & \multicolumn{4}{|c|}{ Clinical investigator, allergist, and experienced infusion nurse available throughout all infusions } \\
\hline & \multicolumn{4}{|c|}{ Obtain vital signs before infusion begins and at 30 -min intervals until patient is discharged } \\
\hline
\end{tabular}

IARs, infusion associated reactions.

\section{METHODS}

\section{Patient population}

Patients were eligible if they had been withdrawn from a previous clinical study as a protocol-specified precaution due to the detection of serum $\operatorname{IgE}$ antibodies or skin-test reactivity to agalsidase beta. The study protocols specified that all patients were to be closely monitored during infusions for emergence of symptoms suggestive of IgE-mediated type I hypersensitivity reactions or anaphylactoid reactions and that, if a patient developed such symptoms, the investigator was to contact the Genzyme Pharmacovigilance Department to evaluate the need for assessments of serum IgE antibodies and skin testing to agalsidase beta. At the time the rechallenge study was underway (September 2002 through October 2004), 202 patients with Fabry disease had been treated with agalsidase beta in a completed or ongoing clinical trial. Of 62 clinical-trial patients tested for serum IgE antibodies, two were positive. Of eight clinical-trial patients in whom skin testing was performed, five exhibited positive reactions. Therefore, seven patients were eligible for the rechallenge study; one declined to participate and six were screened. An Ethics Committee or Institutional Review Board approved the protocol at each site, and informed consent was obtained from each patient before screening. At screening, a physical examination, 12-lead electrocardiogram (ECG) and echocardiogram were performed; serum IgE antibody titers and skin testing to agalsidase beta were evaluated; clinical laboratory parameters (blood chemistry, hematology, and urinalysis) and plasma IgG antibodies to agalsidase beta were assessed. Eligible patients could have been excluded on the basis of clinically significant organic disease or cardiac disease requiring $\beta$-adrenergic blocking agents. An inde- pendent Allergy Board was comprised of four Board-certified allergists who reviewed each patient's screening assessments and medical records to determine eligibility for the study; the Board also advised on patient management during the study.

\section{Study design}

This open-label safety study, sponsored by Genzyme Corporation, was conducted at four sites in two countries (France and United States). The maximum duration was 52 weeks; however, if approved by the Allergy Board, patients could discontinue after 24 weeks to transition to ERT with commercial drug outside the study setting.

The rechallenge protocol is summarized in Table 1.

\section{Patient monitoring}

Patients were treated under the direct supervision of the investigator, working with an allergist and experienced personnel, in a clinic setting with ready access to emergency resuscitation equipment. Before, during, and after infusions, vital signs were monitored at least every 30 minutes. Postinfusion, patients were observed in the clinic for 2 hours, which could be reduced to 1 hour after completion of the first eight infusions with no significant adverse reactions.

\section{Prophylactic medications}

Administration of preinfusion prophylactic medications was not allowed for the first four infusions to permit early recognition of acute systemic reactions. Mild or moderate reactions were managed by a 10 -fold reduction in the infusion rate, and, as necessary, the administration of medications. After the first four infusions, prophylactic medications were permitted (see Table 2 for 
Table 2

Recommendations for prophylactic treatment of infusion-associated reactions

\begin{tabular}{|c|c|c|c|}
\hline & $\begin{array}{l}\text { Standard prophylaxis } \\
\text { regimen }\end{array}$ & $\begin{array}{l}\text { Prophylaxis regimen following a single mild or moderate } \\
\text { adverse event, or a recurrent mild adverse event }\end{array}$ & $\begin{array}{l}\text { Prophylaxis regimen following a single severe event, or a } \\
\text { recurrent moderate or severe adverse event }\end{array}$ \\
\hline \multirow[t]{6}{*}{$\begin{array}{l}\text { Preinfusion } \\
\text { medications }\end{array}$} & \multirow[t]{6}{*}{ None } & \multirow[t]{6}{*}{$\begin{array}{l}1 \mathrm{hr}(\text { no }<30 \mathrm{~min}) \text { before infusion } \\
\text { Ibuprofen } 400 \mathrm{mg} \text { PO }\end{array}$} & $\begin{array}{l}\text { Evaluate results of IgE antibody, tryptase and } \\
\text { complement assays, and skin testing. }\end{array}$ \\
\hline & & & $\begin{array}{l}\text { If results are positive, consult with the Allergy Board and } \\
\text { Genzyme Pharmacovigilance to assess subsequent } \\
\text { infusion strategies }\end{array}$ \\
\hline & & & $\begin{array}{l}\text { If results are negative, proceed with the following } \\
\text { regimen: }\end{array}$ \\
\hline & & & $\begin{array}{l}13 \mathrm{hr} \text { prior to infusion } \\
\text { Prednisone } 50 \mathrm{mg} \text { PO }\end{array}$ \\
\hline & & & $\begin{array}{l}7 \mathrm{hr} \text { prior to infusion } \\
\text { Prednisone } 50 \mathrm{mg} \mathrm{PO}\end{array}$ \\
\hline & & & $\begin{array}{l}1 \mathrm{hr}(\text { no }<30 \mathrm{~min}) \text { before infusion } \\
\text { Prednisone } 50 \mathrm{mg} \text { PO } \\
\text { Immediate-acting antihistamine PO } \\
\text { Ibuprofen } 400 \mathrm{mg} \text { PO }\end{array}$ \\
\hline \multirow{3}{*}{$\begin{array}{l}\text { Initial infusion } \\
\text { rate }\end{array}$} & \multirow[t]{3}{*}{$\leq 0.25 \mathrm{mg} / \mathrm{min}^{a}$} & \multirow[t]{3}{*}{$\sim 0.15 \mathrm{mg} / \mathrm{min}^{a}$} & $\sim 0.15 \mathrm{mg} / \mathrm{min}^{a}$ \\
\hline & & & OR \\
\hline & & & $\begin{array}{l}\text { Split dose in half and administer weekly at a rate of } \\
\sim 0.15 \mathrm{mg} / \mathrm{min}\end{array}$ \\
\hline
\end{tabular}

${ }^{a}$ Increase infusion rate incrementally if infusion proceeds without incident.

recommended guidelines), and adverse reactions were managed by infusion rate reductions and/or medication, as appropriate.

\section{Infusion procedures}

For the first two infusions, agalsidase beta was administered at a dose of $0.5 \mathrm{mg} / \mathrm{kg}$ (half the standard dose). The first two infusions were separated by an interval of 1 week. These infusions were initiated at a rate of no more than $0.01 \mathrm{mg} /$ minute for the first 30 minutes $(1 / 25$ the standard recommended initial rate). If the infusion proceeded without significant symptoms, the infusion rate was doubled every 30 minutes, up to a maximum of $0.25 \mathrm{mg} /$ minute, as tolerated. After successful completion of the first two graded infusions, the standard dosage regimen of $1 \mathrm{mg} / \mathrm{kg}$ every 2 weeks could be instituted at the investigator's discretion. If moderate or severe reactions occurred during the first two infusions, the Allergy Board was consulted before a dose increase. For the first eight treatments, infusions were administered at a rate of no more than 0.25 $\mathrm{mg} / \mathrm{minute}$. Subsequently, the rate could be increased at each infusion by up to $0.08 \mathrm{mg} / \mathrm{minute}$, as tolerated, but the minimum infusion duration that was permitted was 2 hours.

\section{Adverse event monitoring}

Adverse events (AEs) were defined in accordance with the International Conference on Harmonisation guidelines ${ }^{7}$ and were considered serious adverse events (SAEs) if the patient outcome was death, life-threatening, hospitalization, disability, or congenital anomaly, or required intervention to prevent permanent impairment. Patients were continuously monitored for AEs, and, before infusions, an $\mathrm{AE}$ assessment was conducted during which patients were questioned about any health problems experienced since their last visit, such as unexplained fever or chills, unusual pain, rash, shortness of breath, or chest tightness. Each $\mathrm{AE}$ was assessed by the investigator for intensity (mild, moderate, or severe) and treatmentrelatedness (not related, or remotely, possibly, probably, or definitely related). Infusion-associated reactions (IARs) were defined as AEs that occurred on the day of treatment and that were assessed as possibly, probably, or definitely related to treatment, exclusive of ECG, echocardiography, and laboratory abnormalities. AEs were coded using the Medical Dictionary for Regulatory Activities, version 8.1. Only AEs and SAEs that were treatment-emergent, defined as onset on or after the first study infusion, are reported here.

\section{Hypersensitivity assessments}

If a patient experienced a moderate or severe $\mathrm{AE}$ during an infusion, blood samples were drawn within 2 hours of the event for assay of serum tryptase levels (an indicator of mast cell degranulation) and/or plasma complement activation. If evaluation of serum IgE antibodies was indicated, either a preinfusion blood sample was analyzed or a sample was obtained between 3 and 8 days after the event. Samples were processed at the site and shipped to Genzyme's Clinical Specialty Laboratories (Framingham, MA) for analysis. Complement components and tryptase concentrations were assayed using commercially available kits. An indirect ELISA was used to detect IgE antibodies to agalsidase beta. Skin testing was conducted at the study site using clinical-grade agalsidase beta. Prick testing was performed first, followed by intradermal testing only in 
cases of negative reactions to prick testing. The results of hypersensitivity assessments were reported to the investigator before the patient's next infusion.

\section{Clinical laboratory assessments}

At screening and Weeks 12, 26, and 52, a physical examination, ECG, and laboratory evaluations were conducted; an echocardiogram was performed at screening and Weeks 26 and 52. Analyses were performed locally. At screening and before every infusion, serum samples were obtained for titering of IgG antibodies to agalsidase beta by Genzyme’s Clinical Specialty
Laboratories using an ELISA in conjunction with radioimmunoprecipitation, as previously described. ${ }^{4}$

\section{RESULTS}

\section{Patient population}

All six participants were male Caucasians, ranging from 26 to 66 years of age at screening (Table 3 ). The IARs that led to skin testing or IgE antibody testing of these patients in a previous clinical trial of agalsidase beta, along with the results of the testing, are presented in Table 3. The interval between the

Table 3

Patient profiles before and during rechallenge

\begin{tabular}{|c|c|c|c|c|c|c|c|c|c|}
\hline \multirow[b]{2}{*}{ Patient } & \multicolumn{4}{|c|}{ Patient data from previous agalsidase beta study } & \multicolumn{5}{|c|}{ Patient data from rechallenge study } \\
\hline & $\begin{array}{l}\text { Study } \\
\text { infusions }{ }^{a} \\
\text { (n) }\end{array}$ & $\begin{array}{l}\text { IARs leading to } \\
\text { hypersensitivity } \\
\text { testing }\end{array}$ & $\begin{array}{l}\text { Serum } \\
\text { IgE } \\
\text { result }\end{array}$ & $\begin{array}{l}\text { skin } \\
\text { test result }\end{array}$ & $\begin{array}{l}\text { Age at } \\
\text { screening } \\
\text { (yr) }\end{array}$ & $\begin{array}{l}\text { Days off } \\
\text { therapy } \\
\text { between } \\
\text { studies }\end{array}$ & IAR profile during study & $\begin{array}{l}\text { Study } \\
\text { infusions } \\
\text { (n) }\end{array}$ & Rechallenge outcome \\
\hline 1 & 5 & $\begin{array}{l}\text { Hypotension, rhonchi, } \\
\text { chills, pyrexia, } \\
\text { nausea, vomiting }\end{array}$ & Positive $^{c}$ & Not available & 66 & 454 & $\begin{array}{l}\text { Hypotension, hypertension, } \\
\text { chills, dizziness, } \\
\text { dyspnoea, headache, } \\
\text { myalgia, hyperhidrosis, } \\
\text { urinary incontinence }\end{array}$ & 27 & $\begin{array}{l}\text { Received } 25 \text { infusions } \\
\text { at } 1-\mathrm{mg} / \mathrm{kg} \text { dose; } \\
\text { began commercial } \\
\text { therapy after } \\
\text { completing study }\end{array}$ \\
\hline 2 & 45 & $\begin{array}{l}\text { Rash, pruritus, } \\
\text { erythema, pallor, } \\
\text { flushing, chills, } \\
\text { hyperthermia, } \\
\text { blood pressure } \\
\text { increased, } \\
\text { abdominal pain, } \\
\text { nausea, vomiting }\end{array}$ & Negative & Positive & 33 & 549 & $\begin{array}{l}\text { Urticaria, pruritus, } \\
\text { erythema, laryngeal } \\
\text { obstruction, chills, } \\
\text { abdominal pain, } \\
\text { vomiting }\end{array}$ & 18 & $\begin{array}{l}\text { Received } 8 \text { infusions } \\
\text { at } 1-\mathrm{mg} / \mathrm{kg} \text { dose; } \\
\text { began commercial } \\
\text { therapy after } \\
\text { completing study }\end{array}$ \\
\hline 3 & 8 & $\begin{array}{l}\text { Urticaria, feeling hot, } \\
\text { pruritus, nasal } \\
\text { congestion }\end{array}$ & Negative & Positive & 26 & 1159 & Diarrhoea & 16 & $\begin{array}{l}\text { Received } 14 \text { infusions } \\
\text { at } 1-\mathrm{mg} / \mathrm{kg} \text { dose; } \\
\text { began commercial } \\
\text { therapy after } \\
\text { completing study }\end{array}$ \\
\hline 4 & 53 & $\begin{array}{l}\text { Urticaria, livedo } \\
\text { reticularis, upper } \\
\text { respiratory tract } \\
\text { congestion, chills }\end{array}$ & Negative & Positive & 50 & 13 & Urticaria & 14 & $\begin{array}{l}\text { Received } 14 \text { infusions } \\
\text { at } 0.5-\mathrm{mg} / \mathrm{kg} \text { dose; } \\
\text { completed } 6 \\
\text { months of } \\
\text { protocol and } \\
\text { allowed to } \\
\text { transition to } \\
\text { commercial } \\
\text { therapy }\end{array}$ \\
\hline 5 & 74 & $\begin{array}{l}\text { Urticaria, face } \\
\text { oedema, rash, } \\
\text { pruritus, vomiting, } \\
\text { diarrhoea, } \\
\text { abdominal pain, } \\
\text { vascular access } \\
\text { complication }\end{array}$ & Negative & Positive & 33 & 443 & $\begin{array}{l}\text { Urticaria, face oedema, } \\
\text { rash, pruritus, nausea, } \\
\text { vomiting }\end{array}$ & 4 & $\begin{array}{l}\text { Received } 2 \text { infusions } \\
\text { at } 1-\mathrm{mg} / \mathrm{kg} \text { dose; } \\
\text { withdrew due to } \\
\text { recurrence of IARs } \\
\text { and began } \\
\text { commercial therapy } \\
\text { at } 0.5-\mathrm{mg} / \mathrm{kg} \text { dose }\end{array}$ \\
\hline 6 & 21 & $\begin{array}{l}\text { Urticaria, rash, chills, } \\
\text { pyrexia, headache }\end{array}$ & Negative & Positive & 53 & 186 & $\begin{array}{l}\text { Urticaria, bronchospasm, } \\
\text { cough, feeling hot, } \\
\text { hypertension, pyrexia, } \\
\text { insomnia, nausea, } \\
\text { vomiting }\end{array}$ & 1 & $\begin{array}{l}\text { Withdrew due to } \\
\text { recurrence of IARs; } \\
\text { began commercial } \\
\text { therapy after } \\
\text { kidney } \\
\text { transplantation }\end{array}$ \\
\hline
\end{tabular}

\footnotetext{
${ }^{a}$ Only infusions of agalsidase beta are counted for patients who were originally randomized to placebo.

${ }^{b}$ Includes all IARs experienced during the study by each patient except Patient 3 for whom are listed only IARs experienced during Infusion 8 that led to skin testing. ${ }^{c}$ Serum tryptase was elevated at $19.1 \mu \mathrm{g} / \mathrm{L}$ (normal: $5.6-13.5 \mu \mathrm{g} / \mathrm{L}$ ).
} 
last infusion in the previous trial and the first infusion in the rechallenge study varied from 0.4 to 38.1 months.

\section{Rechallenge outcomes}

Results for the six patients are summarized in Table 3. Overall, four patients progressed to the standard dose of $1.0 \mathrm{mg} / \mathrm{kg}$ after two infusions at $0.5 \mathrm{mg} / \mathrm{kg}$, whereas two patients did not receive the standard dose during the study. Of the four who progressed to $1 \mathrm{mg} / \mathrm{kg}$, Patients 1 and 3 received, respectively, 25 and 14 infusions at the standard dose; Patient 2 received eight infusions at $1 \mathrm{mg} / \mathrm{kg}$ before reverting to $0.5 \mathrm{mg} / \mathrm{kg}$; Patient 5 withdrew voluntarily after two infusions at $1 \mathrm{mg} / \mathrm{kg}$ because of the recurrence of IARs. Of the two patients who did not progress to the standard dose, Patient 4 received a total of 14 infusions at $0.5 \mathrm{mg} / \mathrm{kg}$ and withdrew per protocol at 6 months, and Patient 6 withdrew after his first infusion at $0.5 \mathrm{mg} / \mathrm{kg}$ because of recurrence of IARs. All six patients were able to transition to therapy with commercial drug within approximately 1 to 15 months after completing or withdrawing from the study.

\section{Treatment-emergent adverse events}

No deaths occurred and no anaphylactic reactions were experienced during the study. A total of 79 AEs, including four SAEs, were reported. All events were assessed as mild or moderate in intensity; none was severe. Approximately $42 \%$ of the AEs were assessed by the investigator as not related to treatment, and, of the 46 events that were considered treatmentrelated, 43 were IARs that occurred during 19 infusions. Each of the six patients experienced one or more IARs during one or more infusions. The most common IARs were urticaria (six events/four patients), vomiting (three events/three patients), nausea (four events/two patients), chills (three events/two patients), pruritus (two events/two patients), and hypertension (two events/two patients). For a given patient, the IARs experienced during the rechallenge study were generally similar to those experienced in an earlier study (see Table 3). Epinephrine or theophylline was not administered to any patient for treatment of any IAR. For nine of the 19 infusions during which an IAR was reported, the infusion rate was reduced but the infusion was not interrupted and no medication was administered; four were managed by a temporary interruption in the infusion and five were managed by medication or intravenous fluid therapy with or without interruption of the infusion. Only one infusion was terminated before the total dose was administered (the first infusion of Patient 6, described below).

Four SAEs were reported for three patients: for Patient 1, hypotension was reported as an SAE of moderate intensity during his 14th infusion. The patient's heart rate and blood pressure declined from preinfusion values of $89 \mathrm{bpm}$ and $151 / 85 \mathrm{mmHg}$ to $48 \mathrm{bpm}$ and $97 / 28 \mathrm{mmHg}$, respectively, approximately 10 minutes into the infusion. The infusion was interrupted. The patient was placed in the Trendelenburg position and treated with intravenous fluids. After 1.5 hours, his blood pressure and heart rate stabilized at $114 / 68 \mathrm{mmHg}$ and $77 \mathrm{bpm}$, respectively. The infusion was restarted and com- pleted without further incident. Neither elevation of serum tryptase nor activation of plasma complement was observed in association with the event. For Patient 6, nine AEs were reported during his first infusion (see Table 3), including urticaria and bronchospasm of moderate and mild intensity, respectively. The infusion was discontinued, and an albuterol nebulizer and desloratadine were administered. The patient received additional treatment with ranitidine and fluticasone propionate, was kept overnight in the postanesthesia care unit for observation, and recovered without sequelae. The patient's serum tested positive for IgE antibodies, but tryptase remained within normal range in samples drawn during the events. Plasma complement, which was normal in a preinfusion sample, was activated in samples obtained after the onset of events. Patient 5 experienced IARs including urticaria, face edema, nausea, and vomiting of mild or moderate intensity during his two initial infusions at $0.5 \mathrm{mg} / \mathrm{kg}$ and two subsequent infusions at $1.0 \mathrm{mg} / \mathrm{kg}$ (see Table 3). A skin test was conducted after the 4th infusion, and the positive result was reported as an SAE of moderate intensity. (Note that the patient had shown positive skin test reactivity to agalsidase beta in a previous study.) In samples drawn during the first three infusions, no elevation of serum tryptase was observed but plasma complement was activated during two of the infusions.

\section{Laboratory assessments}

No abnormalities in ECG or echocardiographic parameters were reported as treatment-related AEs. All observed abnormalities were attributable to Fabry disease, and no clinically significant changes were identified from screening to the end of the study. Similarly, no significant changes in any laboratory parameter were observed. IgG antibodies to agalsidase beta were detected in four patients at screening; two patients ( $\mathrm{Pa}-$ tients 1 and 3) who had discontinued agalsidase beta therapy more than 1 year before screening were seronegative at screening but seroconverted after one or two infusions. All patients were seropositive at withdrawal or study completion.

\section{DISCUSSION}

The results of the rechallenge study indicate that it is possible to reinstate agalsidase beta therapy in patients with Fabry disease who have developed circulating IgE antibodies or skin test reactivity to the recombinant enzyme. Of the six participants, five patients received between 4 and 27 infusions of agalsidase beta; one patient voluntarily withdrew after one infusion. All six, including the patient who received only one infusion, were subsequently able to transition to commercial drug outside of the study. For rechallenge with agalsidase beta, a protocol was designed that adhered to well-established principles for desensitization that have been successfully applied to both small molecules $^{8}$ and protein therapeutics ${ }^{9}$ : first, the initial doses of agalsidase beta and rates of infusion were lower than the standard recommended regimen and were progressively titrated upward in accordance with a patient's tolerance. Second, careful monitoring of the patient and flexible tailoring of dosage regimens and infu- 
sion rates to the individual were key elements in successful rechallenge. Third, preinfusion medications were prohibited during the first four rechallenge infusions to permit early recognition of acute systemic reactions, but prophylactic administration of antipyretics, antihistamines, and/or steroids was subsequently allowed to manage adverse reactions during infusions (Table 2). Of note, a histamine $\mathrm{H}_{2}$ receptor antagonist proved useful in management of the vomiting experienced by one study patient.

The six participants in this study were selected on the basis of serum IgE antibodies or skin-test reactivity to agalsidase beta detected in a previous study. Even though the prognostic value of these immunogenicity analyses is not known, the patients were withdrawn from the studies as a precautionary measure during the clinical development of agalsidase beta therapy. The role of IgE-mediated pathways in the adverse reactions of these patients to ERT remains unclear. No patient experienced anaphylaxis, and, during IARs, there was no evidence of mast cell degranulation, as assessed by serum tryptase levels. Patient 1 had exhibited elevated serum tryptase levels during an IAR in a previous study, and he was IgE-positive at screening for the rechallenge study. Although he experienced IARs during rechallenge, including one SAE, he completed 25 infusions at the standard therapeutic dose of $1 \mathrm{mg} / \mathrm{kg}$ before transitioning to commercial drug upon study completion. Patient 5 completed four rechallenge infusions during which IARs recurred and after which a skin test indicated continued reactivity to agalsidase beta. The patient, who voluntarily withdrew to gain more flexibility in his treatment regimen, continued therapy with commercial drug and is currently receiving agalsidase beta at 1 $\mathrm{mg} / \mathrm{kg} / 2$ weeks without experiencing adverse reactions. Overall, the results of the study indicate that IgE positivity or skintest reactivity to agalsidase beta does not preclude the ability to continue replacement therapy.

IARs of mild or moderate intensity were reported during $24 \%$ of study infusions. Although there was considerable variability within and between individual patients, IARs predominantly involved dermatological and gastrointestinal symptoms, whereas respiratory and cardiovascular symptoms were less common and less frequent. Most of the IARs were resolved by reducing the infusion rate or temporarily interrupting the infusion, whereas the others were managed by the administration of fluids or medications. Terminating an infusion was required only in the case of Patient 6 who experienced nine AEs during his first infusion. This patient voluntarily withdrew, but resumed agalsidase beta therapy approximately 1 year after the rechallenge study, following kidney transplantation.

In Fabry disease, an inherited deficiency of the lysosomal hydrolase, $\alpha \mathrm{GAL}$, leads to chronic accumulation of incompletely catabolized glycolipid substrates in most cell types and the emergence of life-threatening renal, cardiovascular, and cerebrovascular complications in early adulthood. ${ }^{1}$ The advent of ERT with recombinant human $\alpha$ GAL represents a therapeutic advance for patients with this progressive, multisystemic disorder, as disease management previously relied on palliative treatment. Clinical trials have indicated that agalsidase beta may improve clinical outcomes in patients, especially if therapy is initiated before irreversible tissue damage has ensued. 5,10 However, as with ERT for other lysosomal storage disorders, the potential exists for immune responses to the recombinant protein, ${ }^{11,12}$ and, in Fabry disease, this potential is heightened in hemizygous males as they may completely lack endogenous $\alpha$ GAL. Notably, the six patients in this study were males with very low or undetectable levels of endogenous $\alpha \mathrm{GAL}$ activity (data not shown) and all developed IgG antibodies to agalsidase beta. During clinical trials, it has been observed that IARs occur more often in patients who are IgG-positive, but that the frequency and severity of IARs diminish over time in most patients due to infusion rate optimization, preinfusion medication, and, possibly, increased tolerance to the exogenous protein since antibody titers often decline with time..$^{5,10}$ However, a small number of patients experience severe and/or recurrent IARs that sometimes lead to discontinuance of therapy. By following the treatment and monitoring schemes defined in the rechallenge protocol, it may be possible to successfully rechallenge these patients and reinstate long-term therapy with agalsidase beta.

\section{ACKNOWLEDGMENTS}

This study was sponsored by Genzyme Corporation, Cambridge, MA.

The authors acknowledge the contributions to this work by Karelle Benistan, MD (Hôpital Raymond Poincaré, Garches, France) and Susan M. Richards, PhD, Sunita Goyal, MD, and Mathilde Kaper, MA (Genzyme Corporation, Cambridge, MA, USA).

\section{References}

1. Desnick RJ, Ioannou YA, Eng CM. Alpha-galactosidase A deficiency: Fabry disease. In: Scriver CR, Beaudet A, Sly W, Valle D, et al., editors. Metabolic and molecular bases of inherited disease, 8th ed. New York: McGraw Hill, 2001:3733-3774.

2. Keating GM, Simpson D. Agalsidase beta: A review of its use in the management of Fabry disease. Drugs 2007;67:435-455.

3. Eng CM, Guffon N, Wilcox WR, Germain DP, et al. Safety and efficacy of recombinant human alpha-galactosidase A—replacement therapy in Fabry's disease. N Engl J Med 2001;345:9-16.

4. Wilcox WR, Banikazemi M, Guffon N, Waldek S, et al. Long-term safety and efficacy of enzyme replacement therapy for Fabry disease. Am J Hum Genet 2004;75:65-74.

5. Germain DP, Waldek S, Banikazemi M, Bushinsky DA, et al. Sustained, long-term renal stabilization after 54 months of agalsidase beta therapy in patients with Fabry disease. J Am Soc Nephrol 2007;18:1547-1557.

6. Wilcox WR, Oliveira JP, Hopkin RJ, Ortiz A, et al. Females with Fabry disease frequently have major organ involvement: lessons from the Fabry Registry. Mol Genet Metab 2008;93:112-128.

7. www.fda.gov/cder/guidance/959fnl.

8. Chiaramonte JS, Pinsker W. Specific rush desensitization to carbenicillin: case report. Ann Allergy 1978;41:111-112.

9. Dioun AF, Ewenstein BM, Geha RS, Schneider LC. IgE-mediated allergy and desensitization to factor IX in hemophilia B. J Allergy Clin Immunol 1998;102:113-117.

10. Banikazemi M, Bultas J, Waldek S, Wilcox WR, et al. Agalsidase beta therapy for advanced Fabry disease: a randomized trial. Ann Intern Med 2007;146:77-86.

11. Linthorst GE, Hollak CE, Donker-Koopman WE, Strijland A, et al. Enzyme therapy for Fabry disease: neutralizing antibodies toward agalsidase alpha and beta. Kidney Int 2004;66:1589-1595.

12. Brooks DA, Kakavanos R, Hopwood JJ. Significance of immune response to enzyme-replacement therapy for patients with a lysosomal storage disorder. Trends Mol Med 2003;9:450-453. 